\title{
Stem cells in intervertebral disc regeneration-more talk than action?
}

\author{
Petra KRAUS ${ }^{1, *}$; ANkita SAMANTA ${ }^{1}$; Sina LUFKIN ${ }^{2}$; Thomas LUFKIN ${ }^{1}$ \\ 1 Department of Biology, Clarkson University, Potsdam, NY 13699, USA \\ 2 The Clarkson School, Clarkson University, Potsdam, NY 13699, USA
}

Key words: Stem cells, MSC, Intervertebral disc (IVD), Exosome, Extracellular matrix (ECM)

\begin{abstract}
Pain and lifestyle changes are common consequences of intervertebral disc degeneration (IVDD) and affect a large part of the aging population. The stemness of cells is exploited in the field of regenerative medicine as key to treat degenerative diseases. Transplanted cells however often face delivery and survival challenges, especially in tissues with a naturally harsh microniche environment such as the intervertebral disc. Recent interest in the secretome of stem cells, especially cargo protected from microniche-related decay as frequently present in degenerating tissues, provides new means of rejuvenating ailing cells and tissues. Exosomes, a type of extracellular vesicles with purposeful cargo gained particular interest in conveying stem cell related attributes of rejuvenation, which will be discussed here in the context of IVDD.
\end{abstract}

$\begin{array}{ll}\text { Abbreviations } \\ \text { AF: } & \text { Annulus fibrosus } \\ \text { CEP: } & \text { Cartilaginous endplates } \\ \text { CLBP: } & \text { Chronic low back pain } \\ \text { ECM: } & \text { Extracellular matrix } \\ \text { ESC: } & \text { Embryonic stem cells } \\ \text { EV: } & \text { Extracellular vesicles } \\ \text { iPSC: } & \text { Induced pluripotent stem cells } \\ \text { IVD: } & \text { Intervertebral disc } \\ \text { IVDD: } & \text { IVD degeneration } \\ \text { MSC: } & \text { Mesenchymal stem cells } \\ \text { MVB: } & \text { Multivesicular bodies } \\ \text { NC: } & \text { Notochord } \\ \text { NP: } & \text { Nucleus pulposus } \\ \text { TDSC: } & \text { Transdifferentiated somatic cells }\end{array}$

\section{Introduction}

Tissues and organs of the aging human body originate from a fertilized oocyte. As this totipotent single cell zygote embarks on its journey of life, most daughter cells will succumb to terminal differentiation eventually followed by death (Kraus and Lufkin, 2017). A few, so called stem cells, retain their potential to divide along with a degree of multipotency

*Address correspondence to: Petra Kraus, pkraus@clarkson.edu Received: 22 July 2021; Accepted: 18 August 2021
(Pittenger et al., 1999; Lander, 2009; Sng and Lufkin, 2012). Harnessing or blocking "stemness" is an intriguing approach taken by the fields of regenerative medicine and oncology alike to replenish ailing tissues and organs such as a degenerating intervertebral disc (IVD) or to stop malignant cell growth (Sng and Lufkin, 2012; Sivakamasundari and Lufkin, 2013; Kraus et al., 2017; Li et al., 2019). Regenerative attempts include transplantation of embryonic stem cells (ESC), induced pluripotent stem cells (iPSC) and transdifferentiated somatic cells (TDSC) (Jopling et al., 2011; Xia et al., 2019; Wang et al., 2021), all however pose risks of tumorigenesis. Furthermore, iPSC and TDSC might be impractical and uneconomical if derived de-novo for each patient (Kamao et al., 2014); ESC bear ethical concerns and TDSC are ideally based on detailed knowledge of interacting signaling pathways, which is still lacking for most vertebrate cell types. Autologous or allogeneic mesenchymal stem cells (MSC) however might take in cues from their environment to mold their multipotent potential into the necessary cell type, or, as recently demonstrated, send cues to residual stem cell populations to refurbish ailing tissue (Chen et al., 2010; Sun et al., 2020; Zhang et al., 2020; Luo et al., 2021).

\section{Do MSC live up to expectations?}

As of mid-July 2021, a searchable database for worldwide clinical trials lists 1292 hits for "mesenchymal stem cell" including a wide range of treatments such as acute organ failure, stroke, autoimmune disease, diabetes, arthritis, bone fracture, congenital disease, respiratory distress syndrome, 
cancer and more, with 77 studies currently listed in phase 3 clinical trials (https://clinicaltrials.gov).

As an example, a healthy IVD is crucial for normal spine function where it acts as a semi-moveable joint and provides means of shock absorption to protect adjacent vertebral bodies (Humzah and Soames, 1988; Christ and Wilting, 1992). IVDs are composed of a hydrogel-like, inner nucleus pulposus (NP) rich in extracellular matrix (ECM) that is encapsulated in the annulus fibrosus (AF) and sandwiched by cartilaginous endplates (CEP) (Bibby et al., 2001; Sivakamasundari and Lufkin, 2012; Sivakamasundari and Lufkin, 2013). Cells residing in the avascular, noninnervated NP are sparse in a large amount of ECM and depend on diffusion for survival and communication (Urban et al., 1977; Urban et al., 2004; Binch et al., 2015). This creates a niche low in nutrients, oxygen and $\mathrm{pH}$ fueled by anaerobic lactic acid fermentation (Urban et al., 2004; Wuertz et al., 2008; Liang et al., 2012). Severe and chronic low back pain (CLBP) caused by age-related IVDD presents a huge socio-economic burden worldwide (DePalma et al., 2011; GBD, 2018). Classic treatments of IVDD symptoms are surgical such as discectomy or non-surgical like physiotherapy combined with pain relieving medication (Raj, 2008), the latter contributing to an already overwhelming opiate crisis (Film, 2020). Bioengineering strategies aim for disc repair with injectable hydrogels or replacement with implanted synthetic or natural scaffolds such as polyethylene glycol or alginate, respectively, amongst many others as reviewed in (van Uden et al., 2017) sometimes seeded with cells or supplemented with growth factors (Kim et al., 2020). The IVD is a welcome target for regenerative approaches as IVDD symptoms typically develop over time without posing an immediate life-threatening situation. This permits the establishment and screening of autologous or allogeneic cell lines for disc refurbishment (Baksh et al., 2004; Xu et al., 2017). Delivering notochord (NC) cells, healthy NP cells or stem cells to an ailing disc could address IVDD at its roots (McCann et al., 2011). In recent years much hope was placed on the injection of MSC with many ongoing clinical trials nearing completion, aiming to increase ECM content of aging discs to restore original disc height. Of 385 ongoing studies listed for IVDD 34 apply stem cells in some form. Earlier clinical studies involving MSC as reviewed in Sakai and Schol (2017) reported pain relief and increased disc hydration but no improved disc height. A study involving reactivated NP cells after MSC coculture achieved pain relief without deteriorating disc height (Blanco et al., 2010). More recently, a study sponsored by Bioheart, Inc. using adipose stem cells to assess safety and efficacy has pending results despite completion in 2017 (NCT02097862). Recent phase 2 data for the Mesoblast sponsored CASCADE phase 3 clinical trial using the mesenchymal precursor cell-based product Rexlemestrocel-1 for CLBP suggests a potentially safe and effective treatment (Kraus and Lufkin, 2017; Amirdelfan et al., 2021). NOVOCART ${ }^{\varpi}$ disc, an active phase $1 / 2$ study investigating an autologous disc chondrocyte transplantation system sponsored by Tetec AG is expected to post results soon (NCT01640457) (Tschugg et al., 2017; Li et al., 2019). However, as straight forward as stem cell based approaches might seem, the microenvironment in the aging disc is harsh and presents an obstacle for cell survival, either native or transplanted (Sivakamasundari and Lufkin, 2013). While data from preclinical animal models showed promising results in restoring a disc phenotype (Sakai et al., 2003; Crevensten et al., 2004; Sakai et al., 2005; Henriksson et al., 2009), whether MSC live up to their expectations in IVDD therapy will depend on the outcome of further clinical trials and their long term follow up.

\section{Exosomes-a way of "talking" long distance?}

Homeostasis of a microenvironment is naturally maintained through effective cell-cell communication. IVD cells are sparsely embedded in a large amount of ECM as presented in Figs. 1A and 1B. NP cells reside in an avascular, noninnervated environment as presented in Fig. 1B requiring other communication skills (Liebscher et al., 2011; Li et al., 2019; Li et al., 2019). Development of large scale “-omics" technologies studying proteins as cells release them into their environment (the secretome) increased our understanding of cell-cell communication, enabling the study of extracellular vesicles (EV) with purposeful cargos of proteins and nucleic acids (Jeppesen et al., 2019). EVs differ in size and origin: Apoptotic bodies $(50 \mathrm{~nm}-5000 \mathrm{~nm})$ and ectosomes (50 nm$1000 \mathrm{~nm}$ ) are generated through outward budding of the plasma membrane, while exosomes (50 nm-150 nm) are generated through the endosomal generation of multivesicular bodies (MVB) (Kowal et al., 2016) as presented in Fig. 1C. Exosomes are generated by most cell types (Edgar, 2016; Kalluri and LeBleu, 2020) and their release into body fluids as well as culture media, generates interest for cancer biomarker identification (Kalluri, 2016; Couto et al., 2018).

The NP is of NC origin (Christ and Wilting, 1992; Choi et al., 2008; Choi and Harfe, 2011; Choi et al., 2012; McCann et al., 2012; Lawson and Harfe, 2015; McCann and Seguin, 2016). Progressive loss or trans-differentiation of NC cells in humans and other species like Bos taurus coincides with the onset of IVDD, while the adult murine NP remains composed of NC cells (Trout et al., 1982; Urban and Roberts, 2003; Vujovic et al., 2006; Gilson et al., 2010; Kraus et al., 2017). Coculture of NC cells with MSC or the use of conditioned NC medium could transform MSC towards a NP-like phenotype (McCann et al., 2011; Purmessur et al., 2011 and recently, bone marrow derived MSC could be differentiated towards a NC phenotype through culture with pulverized porcine NP matrix (Li et al., 2021). Secreted signaling factors likely mediate these effects in vitro (Yang et al., 2008; Strassburg et al., 2010; Ferreira et al., 2021). However, the large distance these factors must travel in the NP-ECM puts them at risk for degradation prior to reaching a target cell. The exosome phospholipid-bilayer would provide necessary protection for signaling molecules. Exosomes isolated from NC conditioned medium showed similar transforming properties (Sun et al., 2020) and the described bidirectional exchange of membrane components via multisize vesicles during NP cell and MSC coculture (Strassburg et al., 2012) supports such mechanisms. While the key-proteome of exosomes was recently identified (Kugeratski et al., 2021), exosome cargo can be specific to the cell line of origin and trigger diverse outcomes in target 

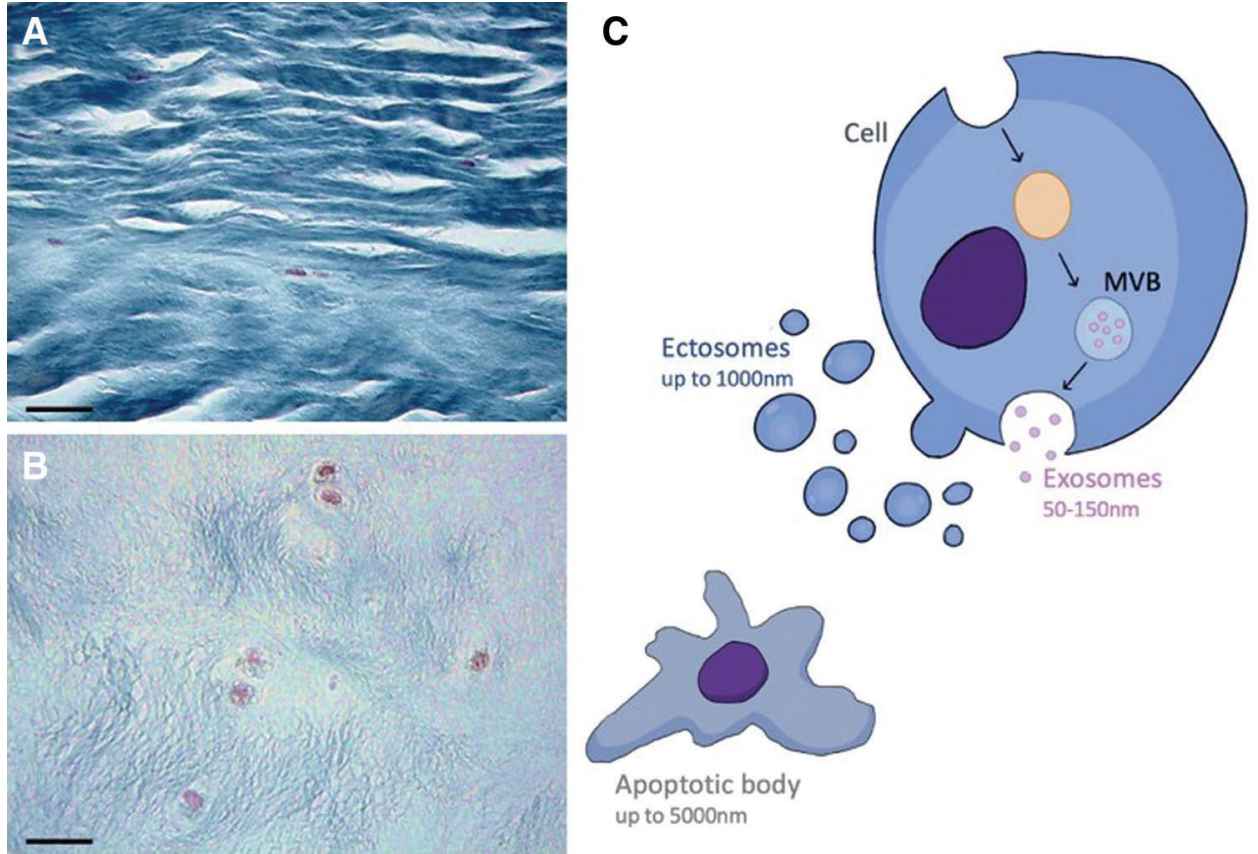

FIGURE 1. Mallory's tetrachrome stain visualizes that cell nuclei (magenta) of the annulus fibrosus (A) and nucleus pulposus (B) of a mature bovine IVD are sparse in a vast amount of extracellular matrix (blue) requiring long-distance communication of some kind. Bar $=50 \mu \mathrm{M}$. $(\mathrm{C})$ Extracellular vesicles (EV) are generated by apoptosis (apoptotic bodies) through membrane budding (ectosomes) or the endosome pathway (exosomes). Exosomes are released into the extracellular environment when multivesicular bodies (MVB) fuse with the plasma membrane.

cells (Edgar, 2016; Kalluri and LeBleu, 2020). But can exosomes travel through the dense ECM meshwork in vivo? It seems theoretically possible (Lenzini et al., 2020). An ongoing clinical trial sponsored by the Dr Himanshu Bansal Foundation using platelet derived exosomes to treat IVDD might provide in vivo practical evidence by Spring 2022 (NCT04849429).

\section{Future outlook}

Many cells receive critical cues from the ECM. Mimicking these conditions in vitro requires elaborate hydrogels or scaffolds and even mechanical cues on top of media supplements. Hence maintaining a cell's phenotype in culture can be more challenging than isolating it. Achieving critical cell numbers for therapy through expansion creates a dilemma between practical $2 \mathrm{D}$ and $3 \mathrm{D}$ culture, the latter being required for phenotypical identity. Recently, many of the attributes of MSC in tissue regeneration are projected on cell-cell communication or "talking" of MSC to endogenous stem cells through means such as exosome cargo instead of "action" in the form of homing and replication of MSC in the target tissue (Richardson et al., 2016; Croft et al., 2021). If exosome application can replace cell-transplantation, conditioned medium could be harvested from cells maintained in 3D culture, minimizing therapeutic cell loss in non-permissive endogenous environments or through immunogenic rejection.

Cells in the IVD find themselves in the unique situation of being very distant from their neighbors without the usual lifelines of communication (Vadala et al., 2019). In that context it seems plausible that peptides, proteins, and nucleic acids get deposited into vesicles like exosomes for a protected journey. The exosome concept might be further exploited in IVD therapies (Piazza et al., 2020) with natural or synthetic exosomes loaded with therapeutic cargo for safely delivering anti-inflammatory cytokines, transcription factors, growth factors and means to regulate metalloproteases. Such exosome focused therapies could circumvent some of the problems associated with stem cell transplantation such as rejection or tumor formation and reduce stem cell tourism due to national laws currently restricting many stem cell therapies in the US, Canada and Europe for ethical or safety concerns (Master and Resnik, 2011; Brown, 2012). As an example, the use of embryonic stem cells is seen as unethical by many, while harvesting exosomes from conditioned medium might receive less criticism. Lastly, a long ongoing quest for biomarkers defining IVD cell populations (Gilson et al., 2010; Minogue et al., 2010; Minogue et al., 2010; Risbud et al., 2015; Thorpe et al., 2016; Richardson et al., 2017; van den Akker et al., 2017; Kraus et al., 2019; Li et al., 2019; Li et al., 2019; van den Akker et al., 2020) might be addressed through the analysis of exosome cargo, just as it has been done in the field of cancer diagnostics (Makler and Asghar, 2020).

Acknowledgement: The funders are thanked for support of this writing.

Author Contributions: The authors confirm responsibility for the following: study conception and design and manuscript preparation.

Ethics Approval: No approval committees were required for this study.

Funding Statement: This work was supported by the Bayard and Virginia Clarkson Endowment Fund and NIH HD099588 both granted to Thomas Lufkin. The funders had no role in study design, data collection and analysis, decision to 
publish, or preparation of the manuscript. The contents are solely the responsibilities of the authors and do not necessarily represent the official views of the NIH.

Conflicts of Interest: The authors declare that they have no conflicts of interest to report regarding the present study.

\section{References}

Amirdelfan K, Bae H, McJunkin T, DePalma M, Kim K et al. (2021). Allogeneic mesenchymal precursor cells treatment for chronic low back pain associated with degenerative disc disease: A prospective randomized, placebo-controlled 36month study of safety and efficacy. Spine Journal 21: 212230. DOI 10.1016/j.spinee.2020.10.004.

Baksh D, Song L, Tuan RS (2004). Adult mesenchymal stem cells: Characterization, differentiation, and application in cell and gene therapy. Journal of Cellular and Molecular Medicine 8: 301-316. DOI 10.1111/j.1582-4934.2004.tb00320.x.

Bibby SR, Jones DA, Lee RB, Yu J, Urban JPG (2001). The pathophysiology of the intervertebral disc. Joint Bone Spine 68: 537-542. DOI 10.1016/S1297-319X(01)00332-3.

Binch AL, Cole AA, Breakwell LM, Michael AL, Chiverton N et al. (2015). Nerves are more abundant than blood vessels in the degenerate human intervertebral disc. Arthritis Research \& Therapy 17: 4. DOI 10.1186/s13075-015-0889-6.

Blanco JF, Graciani IF, Sanchez-Guijo FM, Muntion S, HernandezCampo P et al. (2010). Isolation and characterization of mesenchymal stromal cells from human degenerated nucleus pulposus: Comparison with bone marrow mesenchymal stromal cells from the same subjects. Spine (Phila $\mathrm{Pa}$ 1976) 35: 2259-2265. DOI 10.1097/BRS.0b013e3181cb8828.

Brown C (2012). Stem cell tourism poses risks. Canadian Medical Association Journal 184: E121-E122. DOI 10.1503/cmaj.109-4073.

Chen TS, Lai RC, Lee MM, Choo AB, Lee CN et al. (2010). Mesenchymal stem cell secretes microparticles enriched in pre-microRNAs. Nucleic Acids Research 38: 215-224. DOI 10.1093/nar/gkp857.

Choi KS, Cohn MJ, Harfe BD (2008). Identification of nucleus pulposus precursor cells and notochordal remnants in the mouse: Implications for disk degeneration and chordoma formation. Developmental Dynamics 237: 3953-3958. DOI 10.1002/dvdy.21805.

Choi KS, Harfe BD (2011). Hedgehog signaling is required for formation of the notochord sheath and patterning of nuclei pulposi within the intervertebral discs. Proceedings of the National Academy of Sciences of the United States of America 108: 9484-9489. DOI 10.1073/pnas.1007566108.

Choi KS, Lee C, Harfe BD (2012). Sonic hedgehog in the notochord is sufficient for patterning of the intervertebral discs. Mechanisms of Development 129: 255-262. DOI 10.1016/j.mod.2012.07.003.

Christ B, Wilting J (1992). From somites to vertebral column. Annals of Anatomy 174: 23-32. DOI 10.1016/S0940-9602(11)80337-7.

Couto N, Caja S, Maia J, Strano Moraes MC, Costa-Silva B (2018). Exosomes as emerging players in cancer biology. Biochimie 155: 2-10. DOI 10.1016/j.biochi.2018.03.006.

Crevensten G, Walsh AJ, Ananthakrishnan D, Page P, Wahba GM et al. (2004). Intervertebral disc cell therapy for regeneration: Mesenchymal stem cell implantation in rat intervertebral discs. Annals of Biomedical Engineering 32: 430-434. DOI 10.1023/B:ABME.0000017545.84833.7c.
Croft AS, Illien-Junger S, Grad S, Guerrero J, Wangler S et al. (2021). The application of mesenchymal stromal cells and their homing capabilities to regenerate the intervertebral disc. International Journal of Molecular Sciences 22. DOI 10.3390/ijms22073519.

DePalma MJ, Ketchum JM, Saullo T (2011). What is the source of chronic low back pain and does age play a role? Pain Medicine 12: 224-233. DOI 10.1111/j.1526-4637.2010.01045.x.

Edgar JR (2016). Q\&A: What are exosomes, exactly? BMC Biology 14: 329. DOI 10.1186/s12915-016-0268-z.

Ferreira JR, Teixeira GQ, Neto E, Ribeiro-Machado C, Silva AM et al. (2021). IL-1beta-pre-conditioned mesenchymal stem/stromal cells' secretome modulates the inflammatory response and aggrecan deposition in intervertebral disc. European Cells \& Materials Journal 41: 431-543. DOI 10.22203/eCM.v041a28.

Film RJ (2020). Chasing the dragon: Driving the paradigm shift to move beyond opioids. Journal of Orthopaedic \& SportsPhysical Therapy, 1-11. DOI 10.2519/jospt.2020.10210.

GBD. 2018. (2018). GBD, 2017 Disease and Injury Incidence and Prevalence Collaborators: Global, regional, and national incidence, prevalence, and years lived with disability for 354 diseases and injuries for 195 countries and territories, 1990-2017: A systematic analysis for the Global Burden of Disease Study 2017. Lancet 392: 1789-1858. DOI 10.1016/ S0140-6736(18)32279-7.

Gilson A, Dreger M, Urban JP (2010). Differential expression level of cytokeratin 8 in cells of the bovine nucleus pulposus complicates the search for specific intervertebral disc cell markers. Arthritis Research \& Therapy 12: R24. DOI 10.1186/ar2931.

Henriksson HB, Svanvik T, Jonsson M, Hagman M, Horn M et al. (2009). Transplantation of human mesenchymal stems cells into intervertebral discs in a xenogeneic porcine model. Spine (Phila $\mathrm{Pa}$ 1976) 34: 141-148. DOI 10.1097/ BRS.0b013e31818f8c20.

Humzah MD, Soames RW (1988). Human intervertebral disc: Structure and function. Anatomical Record 220: 337-356. DOI 10.1002/(ISSN)1097-0185.

Jeppesen DK, Fenix AM, Franklin JL, Higginbotham JN, Zhang Q et al. (2019). Reassessment of exosome composition. Cell 177: 428-445.e18. DOI 10.1016/j.cell.2019.02.029.

Jopling C, Boue S, Izpisua Belmonte JC (2011). Dedifferentiation, transdifferentiation and reprogramming: Three routes to regeneration. Nature Reviews Molecular Cell Biology 12: 79-89. DOI 10.1038/nrm3043.

Kalluri R (2016). The biology and function of exosomes in cancer. Journal of Clinical Investigation 126: 1208-1215. DOI 10.1172/JCI81135.

Kalluri R, LeBleu VS (2020). The biology, function, and biomedical applications of exosomes. Science 367: eaau6977. DOI 10.1126/science.aau6977.

Kamao H, Mandai M, Okamoto S, Sakai N, Suga A et al. (2014). Characterization of human induced pluripotent stem cellderived retinal pigment epithelium cell sheets aiming for clinical application. Stem Cell Reports 2: 205-218. DOI 10.1016/j.stemcr.2013.12.007.

Kim MJ, Lee JH, Kim JS, Kim HY, Lee HC et al. (2020). Intervertebral disc regeneration using stem cell/growth factor-loaded porous particles with a leaf-stacked structure. Biomacromolecules 21: 4795-4805. DOI 10.1021/acs.biomac.0c00992.

Kowal J, Arras G, Colombo M, Jouve M, Morath JP et al. (2016). Proteomic comparison defines novel markers to characterize 
heterogeneous populations of extracellular vesicle subtypes. Proceedings of the National Academy of Sciences of the United States of America 113: E968-E977. DOI 10.1073/ pnas.1521230113.

Kraus P, Li K, Sipes D, Varden L, Yerden R et al. (2019). Single-Cell Phenotyping of Complex Heterogeneous Tissue. In: Santra TS, Tseng FG (eds.), Handbook of Single Cell Technologies, pp. 1-17. Singapore: Springer.

Kraus P, Lufkin T (2017). Implications for a stem cell regenerative medicine based approach to human intervertebral disk degeneration. Frontiers in Cell and Developmental Biology 5: 762. DOI 10.3389/fcell.2017.00017.

Kraus P, Yerden R, Kocsis V, Lufkin T 2017. RNA in situ hybridization characterization of non-enzymatic derived bovine intervertebral disc cell lineages suggests progenitor cell potential. Acta Histochemica. DOI 10.1016/j.acthis.2016.12.004.

Kugeratski FG, Hodge K, Lilla S, McAndrews KM, Zhou X et al. (2021). Quantitative proteomics identifies the core proteome of exosomes with syntenin-1 as the highest abundant protein and a putative universal biomarker. Nature Cell Biology 23: 631-641. DOI 10.1038/s41556-021-00693-y.

Lander AD (2009). The 'stem cell' concept: Is it holding us back? Journal of Biology 8: 70. DOI 10.1186/jbiol177.

Lawson L, Harfe BD (2015). Notochord to nucleus pulposus transition. Current Osteoporosis Reports 13: 336-341. DOI 10.1007/s11914-015-0284-x.

Lenzini S, Bargi R, Chung G, Shin JW (2020). Matrix mechanics and water permeation regulate extracellular vesicle transport. Nature Nanotechnology 15: 217-223. DOI 10.1038/s41565020-0636-2.

Li D, Zeng Q, Jiang Z, Ding L, Lu W et al. (2021). Induction of notochordal differentiation of bone marrow mesenchymal-derived stem cells via the stimulation of notochordal cellrich nucleus pulposus tissue. Biotechnology Letters 43: 13-24. DOI 10.3892/mmr.2020.11801.

Li K, Kapper D, Mondal S, Lufkin T, Kraus P (2019). Quantitative single-cell transcript assessment of biomarkers supports cellular heterogeneity in the Bovine IVD. Veterinary Sciences 6: 42. DOI 10.3390/vetsci6020042.

Li K, Kapper D, Youngs B, Kocsis V, Mondal S et al. (2017). Potential biomarkers of the mature intervertebral disc identified at the single cell level. Journal of Anatomy 234: 16-32. DOI 10.1111/joa.12904.

Liang CZ, Li H, Tao YQ, Zhou XP, Yang ZR et al. (2012). The relationship between low $\mathrm{pH}$ in intervertebral discs and low back pain: A systematic review. Archives of Medical Science 8: 952-956. DOI 10.5114/aoms.2012.32401.

Liebscher T, Haefeli M, Wuertz K, Nerlich AG, Boos N (2011). Agerelated variation in cell density of human lumbar intervertebral disc. Spine (Phila Pa 1976) 36: 153-159. DOI 10.1097/BRS.0b013e3181cd588c.

Luo L, Gong J, Zhang H, Qin J, Li C et al. (2021). Cartilage endplate stem cells transdifferentiate into nucleus pulposus cells via autocrine exosomes. Frontiers in Cell and Developmental Biology 9: 3798. DOI 10.3389/ fcell.2021.648201.

Makler A, Asghar W (2020). Exosomal biomarkers for cancer diagnosis and patient monitoring. Expert Review of Molecular Diagnostics 20: 387-400. DOI 10.1080/14737159.2020.1731308.

Master Z, Resnik DB (2011). Stem-cell tourism and scientific responsibility. Stem-cell researchers are in a unique position to curb the problem of stem-cell tourism. $E M B O$ Reports 12: 992-995. DOI 10.1038/embor.2011.156.

McCann MR, Bacher CA, Seguin CA (2011). Exploiting notochord cells for stem cell-based regeneration of the intervertebral disc. Journal of Cell Communication and Signaling 5: 3943. DOI 10.1007/s12079-010-0116-9.

McCann MR, Seguin CA (2016). Notochord cells in intervertebral disc development and degeneration. Journal of Developmental Biology 4: 3. DOI 10.3390/jdb4010003.

McCann MR, Tamplin OJ, Rossant J, Seguin CA (2012). Tracing notochord-derived cells using a Noto-cre mouse: Implications for intervertebral disc development. Disease Models \& Mechanisms 5: 73-82. DOI 10.1242/dmm.008128.

Minogue BM, Richardson SM, Zeef LA, Freemont AJ, Hoyland JA (2010). Characterization of the human nucleus pulposus cell phenotype and evaluation of novel marker gene expression to define adult stem cell differentiation. Arthritis \& Rheumatism 62: 3695-3705. DOI 10.1002/art.27710.

Minogue BM, Richardson SM, Zeef LA, Freemont AJ, Hoyland JA (2010). Transcriptional profiling of bovine intervertebral disc cells: Implications for identification of normal and degenerate human intervertebral disc cell phenotypes. Arthritis Research \& Therapy 12: R22. DOI 10.1186/ar2929.

Piazza N, Dehghani M, Gaborski TR, Wuertz-Kozak K (2020). Therapeutic potential of extracellular vesicles in degenerative diseases of the intervertebral disc. Frontiers in Bioengineering and Biotechnology 8: 88845. DOI 10.3389/fbioe.2020.00311.

Pittenger MF, Mackay AM, Beck SC, Jaiswal RK, Douglas R et al. (1999). Multilineage potential of adult human mesenchymal stem cells. Science 284: 143-147. DOI 10.1126/science.284.5411.143.

Purmessur D, Schek RM, Abbott RD, Ballif BA, Godburn KE et al. (2011). Notochordal conditioned media from tissue increases proteoglycan accumulation and promotes a healthy nucleus pulposus phenotype in human mesenchymal stem cells. Arthritis Research \& Therapy 13: R81. DOI 10.1186/ar3344.

Raj PP (2008). Intervertebral disc: Anatomy-physiology-pathophysiologytreatment. Pain Practice 8: 18-44. DOI 10.1111/j.15332500.2007.00171.x.

Richardson SM, Kalamegam G, Pushparaj PN, Matta C, Memic A et al. (2016). Mesenchymal stem cells in regenerative medicine: Focus on articular cartilage and intervertebral disc regeneration. Methods 99: 69-80. DOI 10.1016/j.ymeth.2015.09.015.

Richardson SM, Ludwinski FE, Gnanalingham KK, Atkinson RA, Freemont AJ et al. (2017). Notochordal and nucleus pulposus marker expression is maintained by subpopulations of adult human nucleus pulposus cells through aging and degeneration. Scientific Reports 7: 1356. DOI 10.1038/s41598-017-01567-w.

Risbud MV, Schoepflin ZR, Mwale F, Kandel RA, Grad S et al. (2015). Defining the phenotype of young healthy nucleus pulposus cells: Recommendations of the Spine Research Interest Group at the 2014 annual ORS meeting. Journal of Orthopaedic Research 33: 283-293. DOI 10.1002/jor.22789.

Sakai D, Mochida J, Iwashina T, Watanabe T, Nakai T et al. (2005). Differentiation of mesenchymal stem cells transplanted to a rabbit degenerative disc model: Potential and limitations for stem cell therapy in disc regeneration. Spine (Phila Pa 1976) 30: 2379-2387. DOI 10.1097/01.brs.0000184365.28481.e3.

Sakai D, Mochida J, Yamamoto Y, Nomura T, Okuma M et al. (2003). Transplantation of mesenchymal stem cells embedded in Atelocollagen gel to the intervertebral disc: A potential 
therapeutic model for disc degeneration. Biomaterials 24: 3531-3541. DOI 10.1016/S0142-9612(03)00222-9.

Sakai D, Schol J (2017). Cell therapy for intervertebral disc repair: Clinical perspective. Journal of Orthopaedic Translation 9: 8-18. DOI 10.1016/j.jot.2017.02.002.

Sivakamasundari V, Lufkin $\mathrm{T}$ (2012). Bridging the gap: Understanding embryonic intervertebral disc development. Cell \& Developmental Biology 1: 1-7.

Sivakamasundari V, Lufkin T (2013). Stemming the degeneration: IVD stem cells and stem cell regenerative therapy for degenerative disc disease. Advances in Stem Cells 2013: 1-22. DOI 10.5171/2013.724547.

Sng J, Lufkin T (2012). Emerging stem cell therapies: treatment, safety, and biology. Stem Cells International 2012: 1-9. DOI $10.1155 / 2012 / 521343$.

Strassburg S, Hodson NW, Hill PI, Richardson SM, Hoyland JA (2012). Bi-directional exchange of membrane components occurs during co-culture of mesenchymal stem cells and nucleus pulposus cells. PLoS One 7: e33739. DOI 10.1371/ journal.pone.0033739.

Strassburg S, Richardson SM, Freemont AJ, Hoyland JA (2010). Coculture induces mesenchymal stem cell differentiation and modulation of the degenerate human nucleus pulposus cell phenotype. Regenerative Medicine 5: 701-711. DOI 10.2217/rme.10.59.

Sun Z, Liu B, Liu ZH, Song W, Wang D et al. (2020). Notochordalcell-derived exosomes induced by compressive load inhibit angiogenesis via the miR-140-5p/Wnt/beta-catenin axis. Molecular Therapy Nucleic Acids 22: 1092-1106. DOI 10.1016/j.omtn.2020.10.021.

Thorpe AA, Binch AL, Creemers LB, Sammon C, Le Maitre CL (2016). Nucleus pulposus phenotypic markers to determine stem cell differentiation: Fact or fiction? Oncotarget 7: 2189-2200. DOI 10.18632/oncotarget.6782.

Trout JJ, Buckwalter JA, Moore KC, Landas SK (1982). Ultrastructure of the human intervertebral disc. I. Changes in notochordal cells with age. Tissue and Cell 14: 359-369.

Tschugg A, Diepers M, Simone S, Michnacs F, Quirbach S et al. (2017). A prospective randomized multicenter phase I/II clinical trial to evaluate safety and efficacy of NOVOCART disk plus autologous disk chondrocyte transplantation in the treatment of nucleotomized and degenerative lumbar disks to avoid secondary disease: Safety results of Phase I-A short report. Neurosurgical Review 40: 155-162. DOI 10.1007/s10143-016-0781-0.

Urban JP, Holm S, Maroudas A, Nachemson A (1977). Nutrition of the intervertebral disk. An in vivo study of solute transport. Clinical Orthopaedics and Related Research 129: 101-114.

Urban JP, Roberts S (2003). Degeneration of the intervertebral disc. Arthritis Research \& Therapy 5: 120-130. DOI 10.1186/ar629.

Urban JP, Smith S, Fairbank JC (2004). Nutrition of the intervertebral disc. Spine (Phila Pa 1976) 29: 2700-2709.
Vadala G, Ambrosio L, Russo F, Papalia R, Denaro V (2019). Interaction between mesenchymal stem cells and intervertebral disc microenvironment: From cell therapy to tissue engineering. Stem Cells International 2019: 1-15. DOI 10.1155/2019/ 2376172.

van den Akker GGH, Koenders MI, van de Loo FAJ, van Lent P, Blaney Davidson E et al. (2017). Transcriptional profiling distinguishes inner and outer annulus fibrosus from nucleus pulposus in the bovine intervertebral disc. European Spine Journal 26: 2053-2062. DOI 10.1007/ s00586-017-5150-3.

van den Akker GGH, Eijssen LMT, Richardson SM, Rhijn LWV, Hoyland JA et al. (2020). A membranome-centered approach defines novel biomarkers for cellular subtypes in the intervertebral disc. Cartilage 11: 203-220. DOI 10.1177/ 1947603518764260.

van Uden S, Silva-Correia J, Oliveira JM, Reis RL (2017). Current strategies for treatment of intervertebral disc degeneration: Substitution and regeneration possibilities. Biomaterials Research 21: 247. DOI 10.1186/s40824-017-0106-6.

Vujovic S, Henderson S, Presneau N, Odell E, Jacques TS et al. (2006). Brachyury, a crucial regulator of notochordal development, is a novel biomarker for chordomas. Journal of Pathology 209: 157-165. DOI 10.1002/(ISSN)1096-9896.

Wang H, Yang Y, Liu J, Qian L (2021). Direct cell reprogramming: Approaches, mechanisms and progress. Nature Reviews Molecular Cell Biology 22: 410-424. DOI 10.1038/s41580021-00335-z.

Wuertz K, Godburn K, Neidlinger-Wilke C, Urban J, Iatridis JC (2008). Behavior of mesenchymal stem cells in the chemical microenvironment of the intervertebral disc. Spine (Phila $\mathrm{Pa}$ 1976) 33: 1843-1849. DOI 10.1097/BRS.0b013e31817b8f53.

Xia K, Gong Z, Zhu J, Yu W, Wang Y et al. (2019). Differentiation of pluripotent stem cells into nucleus pulposus progenitor cells for intervertebral disc regeneration. Current Stem Cell Research \& Therapy 14: 57-64. DOI 10.2174/1574888X13666180918095121.

Xu L, Liu Y, Sun Y, Wang B, Xiong Y et al. (2017). Tissue source determines the differentiation potentials of mesenchymal stem cells: A comparative study of human mesenchymal stem cells from bone marrow and adipose tissue. Stem Cell Research \& Therapy 8: 87. DOI 10.1186/s13287-017-0716-x.

Yang SH, Wu CC, Shih TT, Sun YH, Lin FH (2008). In vitro study on interaction between human nucleus pulposus cells and mesenchymal stem cells through paracrine stimulation. Spine (Phila $\mathrm{Pa}$ 1976) 33: 1951-1957. DOI 10.1097/ BRS.0b013e31817e6974.

Zhang QC, Hu SQ, Hu AN, Zhang TW, Jiang LB et al. (2021). Autophagy-activated nucleus pulposus cells deliver exosomal miR-27a to prevent extracellular matrix degradation by targeting MMP-13. Journal of Orthopaedic Research 39: 1921-1932. DOI 10.1002/jor.24880. 